\title{
Pattern of admissions, clinical course and short term outcome of patients admitted to an obstetric ICU of a tertiary care hospital of north India: a retrospective study
}

\author{
Waseeqa Nigeen ${ }^{1 *}$, Saima Salam², Samina Ashraf ${ }^{1}$, Abdus Sami Bhat ${ }^{3}$
}

\author{
${ }^{1}$ Department of Health and Family welfare Srinagar, Jammu and Kashmir, India \\ ${ }^{2}$ Department of Gynecology and Obstetrics, Government Lalla Ded Hospital, an associated hospital of Government \\ Medical College Srinagar, Jammu and Kashmir, India \\ ${ }^{3}$ Department of Pediatrics, Government Medical College Srinagar, Jammu and Kashmir, India
}

Received: 24 March 2018

Accepted: 31 March 2018

\section{*Correspondence:}

Dr. Waseeqa Nigeen,

E-mail: samiaiims@gmail.com

Copyright: (c) the author(s), publisher and licensee Medip Academy. This is an open-access article distributed under the terms of the Creative Commons Attribution Non-Commercial License, which permits unrestricted non-commercial use, distribution, and reproduction in any medium, provided the original work is properly cited.

\begin{abstract}
Background: Obstetric ICUs have become an important part of any tertiary care obstetric hospital. There have been studies in different parts of the world including India to determine the clinical spectrum, management and outcome of the patients admitted to these units. There have been a few studies on the subject from our part of the country, so we tried to carry out the said study. Our objective was to study indications of admissions, the pattern of complications, interventions required, and the maternal and fetal /neonatal outcome of the patients admitted in an obstetric ICU of our hospital.

Methods: A retrospective descriptive study carried out at Lalla Ded hospital Srinagar, a tertiary care hospital of north India, between January 2017 and June 2017.

Results: Fifty patients among 4890 obstetric admissions required ICU care giving an admission rate of $1.02 \%$. Most of the patients fell in the age group of 26-30years (52\%) followed by 31-35 years (24\%). The most frequent indication for admission to ICU was pregnancy induced hypertension related eclampsia and preeclampsia which constituted about $44 \%(n=22)$ of the admissions. Obstetric haemorrhage was a close second and accounted for $34 \%(n=17)$ of the admissions. Mean ICU stay was $2.5 \pm 1$ days. Four patients died giving a maternal mortality rate of $8 \%$ in this ICU. There were eleven fetal and neonatal deaths excluding ectopic pregnancy giving a fetal /neonatal mortality rate of $22 \%$.

Conclusions: Obstetric ICUs have become an important part of any tertiary care obstetric hospital. Significant number of patients get admitted and treated in these ICUs. In our part of the world majority of ICU admissions are because of eclampsia/preeclampsia and obstetric haemorrhage. Although a large number of mothers and their neonates get benefitted by way of admission to ICUs, a significant proportion of these mothers and their neonates die. There is a lot of scope of improvement in maternal and perinatal mortality. In addition to the importance of setting up of state of the art obstetric ICUs, the need for supervision of pregnancies, institutional deliveries, early detection of complications and early referral cannot be overemphasized.
\end{abstract}

Keywords: Clinical course, Outcome, Obstetric ICU 


\section{INTRODUCTION}

Although pregnancy is a physiological process, but certain proportion of pregnant women develop complications. Most of these complications are managed outside ICU, however a certain proportion of these women require treatment in an intensive care setup. Obstetric critical care has developed very much in past few decades and obstetric ICU forms an important part of any tertiary care obstetric hospital these days. Earlier these patients were managed in surgical or medical ICUs but now obstetric ICUs have taken over. This is true even in developing countries where these ICUs have come up almost everywhere. These ICUs are widely believed to have made a significant dent in tertiary care maternal mortality and helped in improving pregnancy outcomes.

The most common indications for admissions to these ICUs varies between regions. In some reports from developed countries the common causes of admission include pregnancy related hypertensive disorders, obstetric haemorrhages. ${ }^{1-7}$ In India studies have shown pregnancy related hypertensive disorders, obstetric haemorrhages and sepsis to be common indications for ICU admission. ${ }^{8-13}$ The fetal and maternal outcome in the ICUs also varies between regions. In India the maternal mortality has been reported between $12-33 \%$, while perinatal mortality has been reported as $12-47 \%$. $^{2,6-13}$

Since we did not have many studies regarding the pattern of ICU admissions from our part of the country, we looked into the indications of admissions, the pattern of complications, interventions required and the maternal and fetal /neonatal outcome of the patients admitted in an obstetric ICU of our hospital and tried to compare the data with that of other studies from India and from outside India

\section{METHODS}

This was a retrospective study done over a period of six months between January 2017 to june 2017. This study was done at Government Lalla Ded Hospital Government Medical College Srinagar Jand K India which is a lone tertiary care gynae and obstetric hospital of Kashmir valley catering to whole of its population and some parts of Jammu and Ladakh divisions. It has a dedicated ICU which has a bed strength of 15 and is equipped with 4 ventilators. It is jointly supervised by obstetricians and critical care anesthetists.

Authors collected data pertaining to all the ICU admissions during the specified period from the hospital records and entered the relevant data and information into the predesigned proforma. Data was collected regarding age, residence, parity, booking status, admission diagnosis, complications, investigations during ICU stay, interventions required, fetal, neonatal and maternal outcome.
The data was entered into Microsoft excel sheet and analysed with SPSS 16 software. The results were expressed as percentages and proportions, Outcome was described as death/discharge in mothers and death survival in case of fetus/neonates.

\section{RESULTS}

There was a total of 4890 obstetric admissions over a period of six months in the hospital. The number of admissions in ICU was 50, giving an ICU admission rate of $1.02 \%$, Most of the patients fell in the age group of 2630years (52\%) followed by 31-35 years (24\%). Sixty eight percent women were multigravida while $36 \%$ were primigravida. Maximum patients $40(80 \%)$ were from rural background. More patients were unbooked 30 $(60 \%)$. Sixty five percent patients delivered by caeserian section while $35 \%$ delivered by normal vaginal delivery. Baseline characteristics are given in Table 1.

Table 1: Baseline characteristics.

\begin{tabular}{|ll|}
\hline Baseline characteristics & n $(\%)$ \\
\hline Age & \\
\hline$<20$ & $0(0 \%)$ \\
\hline $20-25$ & $7(14 \%)$ \\
\hline $26-30$ & $26(52 \%)$ \\
\hline $31-35$ & $12(24 \%)$ \\
\hline$>35$ & $5(10 \%)$ \\
\hline Parity & \\
\hline Primi & $16(32 \%)$ \\
\hline Multi & $34(68 \%)$ \\
\hline Location & $10(20 \%)$ \\
\hline Urban & $40(80 \%)$ \\
\hline Rural & \\
\hline Booking status & $20(40 \%)$ \\
\hline Booked & $30(60 \%)$ \\
\hline Unbooked & $32(65 \%)$ \\
\hline Mode of delivery $\mathbf{n = 4 9}$ & $17(35 \%)$ \\
\hline Caesarian & \\
\hline vaginal & \\
\hline
\end{tabular}

The most frequent indication for admission to ICU was pregnancy induced hypertension related eclampsia and preeclampsia which constituted about $44 \%(n=22)$ of the admissions. Obstetric haemorrhage was a close second and accounted for $34 \%(n=17)$ of the admissions. Out of the 17 with obstetric haemorrhage nine had antepartum haemorrhage and eight had postpartum haemorrhage giving an equal frequency of admission to ICU among these.

Two (4\%) patients had septicemia. There were 2 patients each of ruptured uterus and post delivery sudden collapse possibly arrhythmias and one each of achondroplasia, ischemic heart disease, mitral stenosis, myaesthenia gravis, post LSCS hematoma and anaphylaxis. The admission indications are further summarized in Table 2. 
Table 2: Indication for admission.

\begin{tabular}{|ll|}
\hline Indication & n (\%) \\
\hline Eclampsia/preclampsia & $22(44 \%)$ \\
\hline Obstetric haemorrhage & $17(34 \%)$ \\
\hline APH & $8(16 \%)$ \\
\hline Placenta previa only & 3 \\
\hline Placenta accrete/percreta & 2 \\
\hline Placental abruption & 3 \\
\hline PPH & $7(16 \%)$ \\
\hline Septicemia & $2(4 \%)$ \\
\hline Uterine rupture/tear & $2(4 \%)$ \\
\hline Ruptured ectopic & $1(2 \%)$ \\
\hline Miscellanous & $8(16 \%)$ \\
\hline Achondroplasia & 1 \\
\hline Ischemic heart disease & 1 \\
\hline Mitral stenosis & 1 \\
\hline Myaethenia gravis & 1 \\
\hline Post LSCS hematoma & 1 \\
\hline Anaphylaxis & 1 \\
\hline Post delivery sudden collapse? & 2 \\
\hline arrhythmia & \\
\hline Ruptured ectopic not included. & \\
\hline
\end{tabular}

As far as complications are concerned 22 (44\%) had hypertension while $13(26 \%)$ presented as shock mostly haemorrhagic shock in 10. Four (8\%)patients developed disseminated intravascular coagulation. Seizures occurred in 11 patients $(22 \%)$ out of which nine had eclamptic seizures and 2 had non eclamptic seizures.

Table 3: Complications.

\begin{tabular}{|l|l|}
\hline Complications & n $(\%)$ \\
\hline Hypertension & $22(44 \%)$ \\
\hline shock & $13(26 \%)$ \\
\hline $\begin{array}{l}\text { Dissemonated intravascular coagulation } \\
\text { (DIC) }\end{array}$ & $4(8 \%)$ \\
\hline Acute kidney injury & $6(12 \%)$ \\
\hline Acute liver failure & 0 \\
\hline Pulmonary involvement & $6(12 \%)$ \\
\hline Pulmonary edema & 4 \\
\hline ARDS & 1 \\
\hline Pneumonia & 1 \\
\hline Cardiac involvement & $9(18 \%)$ \\
\hline Congestive heart failure & 7 \\
\hline Left ventricular failure & 1 \\
\hline Decreased Ejection fraction & 1 \\
\hline seizures & $11(22 \%)$ \\
\hline Eclamptic seizures & 9 \\
\hline Non eclamptic seizures & 2 \\
\hline Hemoglobin g\% & \\
\hline$>10$ & 10 \\
\hline $7-10$ & 22 \\
\hline$<7$ & 18 \\
\hline $\begin{array}{l}\text { Thrombocytopenia (Platelets }<1 \\
\text { lakh/mm }{ }^{3} \text { ) }\end{array}$ & $8(16 \%)$ \\
\hline Deranged Coagulogram & $4(8 \%)$ \\
\hline
\end{tabular}

Acute Kidney injury (AKI) was found in 6(12\%) of patients. Cardiac and pulmonary involvement was found in 18 and $12 \%$ patients respectively. Moderate to severe anemia was found in almost $60 \%$ of the patients, Thrombocytopenia (platelet count $<1$ lac $/ \mathrm{mm} 3$ ) was found in $8(16 \%)$ of the cases. Coagulogram was deranged in $4(8 \%)$ of the patients. The complications are further summarized in Table 3.

Thirty patients $(60 \%)$ required mechanical ventilation. Mean duration of mechanical ventilation was $1.5 \pm 0.6$ days with a range of 4 hours to 15 days. Ten (20\%) required inotropic support. Mean duration of inotropic support was $2.3 \pm 1$ days. Twenty two (44\%) patients required magnesium sulphate. One patient required dialysis. Antibiotics were given in $35(70 \%)$ of patients. Blood and component transfusion were given in $22(44 \%)$ of patients. The medical interventions are summarized in Table 4

Regarding surgical interventions, caesarean section was done in 20 patients (40\%). These include women with post caesarean complications. Caesarean hysterectomy was done in $8(16 \%)$ of the patients. Uterine artery ligation, laparotomy for ruptured ectopic, vaginal tear repair and exploratory laparotomy for post caesarean hematoma was done in one patient each. Surgical interventions are summarised in Table 4.

Table 4: Interventions carried out.

\begin{tabular}{|l|l|}
\hline Interventions & n $(\%)$ \\
\hline Medical & \\
\hline Ventilation & $30(60 \%)$ \\
\hline Inotropic support & $10(20 \%)$ \\
\hline Magnesium sulphate & $22(44 \%)$ \\
\hline Dialysis & $1(2 \%)$ \\
\hline Antibiotics & $35(70 \%)$ \\
\hline Blood and component transfusion & $22(44 \%)$ \\
\hline Surgical & \\
\hline Caesarean section only & $20(40 \%)$ \\
\hline Hysterectomy & $9(18 \%)$ \\
\hline Uterine artery ligation & $1(2 \%)$ \\
\hline Laporotomy (Ruptured ectopic) & $1(2 \%)$ \\
\hline Vaginal tear repair & $1(2 \%)$ \\
\hline $\begin{array}{l}\text { Exploratory laparotomy and hematoma } \\
\text { drainage }\end{array}$ & $1(2 \%)$ \\
\hline
\end{tabular}

Table 5: Outcome.

\begin{tabular}{|llll|}
\hline & Died & Survived & Mortality \\
\hline Maternal & 4 & 46 & $8 \%$ \\
\hline $\begin{array}{l}\text { Fetal/neonatal (fetal } \\
\text { loss, IUD, still birth) }\end{array}$ & 11 & $38 *$ & $22.4 \%$ \\
\hline
\end{tabular}

Mean ICU stay was $2.5 \pm 1$ days. Four patients died out of 50 admitted in ICU giving a maternal mortality rate of $8 \%$ in this ICU. There were eleven fetal and neonatal 
deaths excluding ectopic pregnancy giving a mortality rate of $22 \%$ (Table 5).

\section{DISCUSSION}

This study is only one among the few studies that have been done in the developing world on this subject. We found that the ICU admission rate was $1.02 \%$ which is very high. The ICU admission rate was found to be 0.4 to $1.2 \%$ in other Indian studies. ${ }^{8-13}$ In developed world the ICU admission rate has been reported to be between 0.7 $13.5 \% .^{4}$ The reason for high ICU admission rate is simply because of poor antenatal supervision, non instituitional deliveries, late recognition of complications and delayed referral.

The most common indication for ICU admission was PIH related disorders including eclampsia and preeclampsia in $44 \%$ of the cases, closely followed by obstetric haemorrhage in another $24 \%$ of the cases. We had sepsis in two patients only (4\%). Pregnancy related hypertensive disorders have been reported as a leading cause of ICU admission in a number of Indian studies. ${ }^{8,9}$ However in some studies obstetric haemorrhage has been reported as the commonest cause of ICU admission. ${ }^{10,12,13}$ In one of the studies septicemia has been found to be the commonest indication for ICU admission. ${ }^{11}$ In developed countries the indications for admissions have varied between centres primarily because of the different referral nature of these hospitals which might be the reason for the observed heterogeneity. The most common indication for ICU admission has been either eclampsia/preclampsia or obstetric haemorrhage. ${ }^{1-7}$ In brief pregnancy related hypertensive disorders and Obstetric haemorrhage together account for majority of the patients admitted to ICU. In addition to direct obstetric causes we had around eight patients who were admitted because of indirect obstetric causes.

A significant proportion of patients presented with hypertension as expected (44\%) because the leading cause of ICU admission was $\mathrm{PIH}$, next in frequency was shock which was present in $26 \%$ of patients and most of which was haemorrhagic because of either APH or PPH. Out of 15 obstetric haemorrhage patients 10 had shock. Two had septic shock and one had shock due to cardiac ailment. Pulmonary, cardiac and renal involvement was found in $12 \%, 12 \%$ and $18 \%$ of the patients respectively. In one of the studies done in India this proportion was found to be 22,25 and $4 \%$ respectively. ${ }^{8}$ The high incidence of renal involvement in present study might partly be due to inclusion of all patients with decreased urine output or oliguria into this group.

Mechanical ventilation was carried out in $60 \%$ of the cases $(n=30)$ while inotropic support was needed in $40 \%$ of the cases $(n=20)$. Dialysis was done in one patient. Mechanical ventilation rates have been higher in other Indian studies to the tune of $87-94 \%{ }^{8,9}$ In one of the studies the inotrope use has been very high in almost $85 \%$ of the cases however another study put it at $40 \% .^{9}$ In studies outside India the mechanical ventilation rate has been reported as 36 and $58 \%$ in two of the studies. ${ }^{3,6}$ The less proportion of patients needing mechanical ventilation and inotropic use in present study might be because of a slightly liberal policy for ICU admission in our hospital. Antibiotics and magnesium sulphate were also used in $70 \%$ and $44 \%$ respectively. The percentage use of antibiotics and magnesium sulphate has varied among studies depending upon the number of PIH and sepsis patients admitted to the ICU. ${ }^{8,9}$

As far as surgical intervention is concerned, only caesarean section was done in 20 patients $(40 \%)$ of the patients, Hysterectomy was done in 9 patients (18\%). Other procedures required rarely were uterine artery ligation, laparotomy for post caesarean hematoma, laparotomy for ectopic pregnancy and vaginal tear repair in one of the patients of PPH.

Maternal mortality in our ICU was $8 \%$ while fetal/neonatal mortality was $22 \%$. In India the maternal mortality has been reported between $12-33 \%$, while perinatal mortality has been reported as $12-47 \% .^{2,6-13}$ Four mothers died ,2 because of PPH, 1 of abruptio placentae and 1 of Uterine rupture. Most of maternal deaths that have occurred in other studies have been because of obstetric haemorrhage., ${ }^{4,8}$ The high fetal/neonatal mortality in our hospital may be accounted by late referral to our centre at which time fetal compromise has already occurred.

\section{CONCLUSION}

Obstetric ICUs have become an important part of any tertiary care obstetric hospital. Significant number of patients get admitted and treated in these ICUs. In our part of the world majority of ICU admissions are because of eclampsia/preeclampsia and obstetric haemorrhage. Although a large number of mothers and their neonates get benefitted by way of admission to ICUs, however a significant proportion of these mothers and their neonates die. There is a lot of scope of improvement in maternal and perinatal mortality. In addition to the importance of setting up of state of the art obstetric ICUs, the need for supervision of pregnancies, institutional deliveries, early detection of complications and early referral cannot be overemphasized.

Funding: No funding sources Conflict of interest: None declared

Ethical approval: The study was approved by the Institutional Ethics Committee

\section{REFERENCES}

1. Wanderer JP, Leffert LR, Mhyre JM, Kuklina EV, Callaghan WM, Bateman BT. Epidemiology of obstetric-related ICU admissions in Maryland: 19992008. Crit Care Med. 2013;41:1844-52. 
2. Ozumba BC, Ajah LO, Obi VO, Umeh UA, Enebe JT, Obioha KC. Pattern and outcome of obstetric admissions into the intensive care unit of a Southeast Nigerian Hospital. Indian J Crit Care Med. 2018;22:16-92.

3. Anwari JS, Butt AA, Al-Dar MA. Obstetric admissions to the intensive care unit. Saudi Med J. 2004 Oct;25(10):1394-9.

4. Pollock W1, Rose L, Dennis CL. Pregnant and postpartum admissions to the intensive care unit: a systematic review.Intensive Care Med. 2010 Sep;36(9):1465-74.

5. Bandeira AR, Rezende CA, Reis ZS, Barbosa AR, Peret FJ, Cabral AC. Epidemiologic profile, survival, and maternal prognosis factors among women at an obstetricintensive care unit. Int $\mathbf{J}$ Gynaecol Obstet. 2014 Jan;124(1):63-6.

6. Leung NY, Lau AC, Chan KK, Yan WW. Clinical characteristics and outcomes of obstetric patients admitted to the Intensive Care Unit: a 10-year retrospective review. Hong Kong Med J. 2010;16(1):18-25.

7. Ng VK, Lo TK, Tsang HH, Lau WL, Leung WC. Intensive care unit admission of obstetric cases: a single centre experience with contemporary update. Hong Kong Med J. 2014;20:24-31.

8. Jain S, Guleria K, Vaid NB, Suneja A, Ahuja S. Predictors and outcome of obstetric admissions to intensive care unit: a comparative study. Indian J Crit Care Med. 2018 Jan;22(1):16-9.

9. Ashraf N, Mishra SK, Kundra P, Veena P, Soundaraghavan S, Habeebullah S. Obstetric patients requiring intensive care: a one year retrospective study in a tertiary care institute in India. Anesthesiol Res Pract. 2014;2014:789450.

10. Dasgupta S, Jha T, Bagchi P, Singh SS, Gorai R, Choudhury SD Critically Ill Obstetric Patients in a General Critical Care Unit: A 5 Years' Retrospective Study in a Public Teaching Hospital of Eastern India. Indian J Crit Care Med. 2017 May;21(5):294-302.

11. Dattaray C, Mandal D, Shankar U, BhattacharyaP, Mandal S. Obstetric patients requiring highdependency unit admission in a tertiary referral centre. Indian J Crit Care Med. 2013 JanFeb;17(1):34-37.

12. Ramachandra Bhat PB, Navada MH, Rao SV, Nagarathna G. Evaluation of obstetric admissions to intensive care unit of a tertiary referral center in coastal India. Indian J Crit Care Med. 2013 Jan;17(1):34-7.

13. Rathod AT, Malini KV. Study of obstetric admissions to the intensive care unit of a tertiary care hospital. J Obstet Gynaecol India. 2016 Oct; 66(Suppl 1):12-7.

Cite this article as: Nigeen W, Salam S, Ashraf S, Bhat AS. Pattern of admissions, clinical course and short term outcome of patients admitted to an obstetric ICU of a tertiary care hospital of north India: a retrospective study. Int J Reprod Contracept Obstet Gynecol 2018;7:1749-53. 